\title{
CPW-Fed KOCH SNOWFLAKE Fractal Antenna for UWB Wireless Applications
}

\author{
Abdelati Reha ${ }^{1 *}$, Abdelkebir El Amri ${ }^{{ }^{* *}}$, Othmane Benhmammouch ${ }^{3}$, Ahmed Oulad Said $^{4}$ \\ ${ }^{1}$ RITM Laboratory, EST CASABLANCA, Hassan II University, Casablanca, Morocco \\ ${ }^{2}$ Mundiapolis University, Nouaceur, Casablanca, Morocco \\ ${ }^{3}$ Royal Air Academy, Marrakech, Morocco \\ *reha.abdelati@gmail.com, ** elamri_abdelkebir@yahoo.fr, \\ 3othmane.benhmammouch@gmail.com, ${ }^{4}$ a_ouladsaid@hotmail.com
}

\begin{abstract}
Four iterations of a Coplanar Waveguide (CPW)-Fed KOCH SNOWFLAKE fractal antenna are studied. Increasing the number of iterations allow us obtaining a simple and miniaturized antenna with good performances, operating for Ultra Wide Band (UWB) applications.

The proposed antennas are a good solution for the 3.7-4.2GHZ C-Band, the 5.15-5.82 Wireless Local Area Network (WLAN), and for the $5 \mathrm{GHZ}$ Worldwide Interoperability for Microwave Access system (WIMAX) applications. The simulation was performed in FEKO 6.3.

Keywords: Fractal antennas, KOCH SNOWFLAKE, Multi-Band, Ultra Wide-Band, UWB, Antenna design.
\end{abstract}

\section{Introduction}

With the proliferation and miniaturization of telecommunications systems and their integration in restricted environments, such as Smart-phones, tablets, cars, airplanes, and other embedded systems. The design of compact multi-bands and Ultra Wide Band (UWB) antennas becomes a necessity.

For designing this kind of antennas, two techniques are used:

1. Designing multi-band antennas operating in several frequencies bands. Several studies have been made to design this kind of antennas by using fractal geometries or adding slots to the radiating elements [1-4].

2. Designing UWB antennas operating in the frequencies bands exceeding $500 \mathrm{MHZ}$ or having a fractional bandwidth of at least 0.20, UWB wireless communication occupies a bandwidth from 3.1 to $10.6 \mathrm{GHz}$ (based on the FCC "Federal Communication 
Commission") [5-12][15]. One of the interesting techniques used is the fractal geometry, because it's a simple technique based on the auto-similarity, the most known techniques used are: Minkowski Island, Koch loop, Pascal's triangle and Sierpinski gaskets... [13-16].

In this paper, we propose a CPW-fed KOCH SNOWFLAKE Fractal slot antenna. The simulation is done by FEKO 6.3 based on the Method of the Moment (MoM) [17].

\section{Antenna Design}

As shown in figure 1, the proposed antenna is printed on a FR4 dielectric substrate of relative permittivity $\varepsilon r=4.4$, thickness $\mathrm{H}=1.6 \mathrm{~mm}$ and fed by a CPW transmission line. Several studies have used this mode of feeding because it's one of the ways to increase the Bandwidth of the antenna [4][7][14][19].

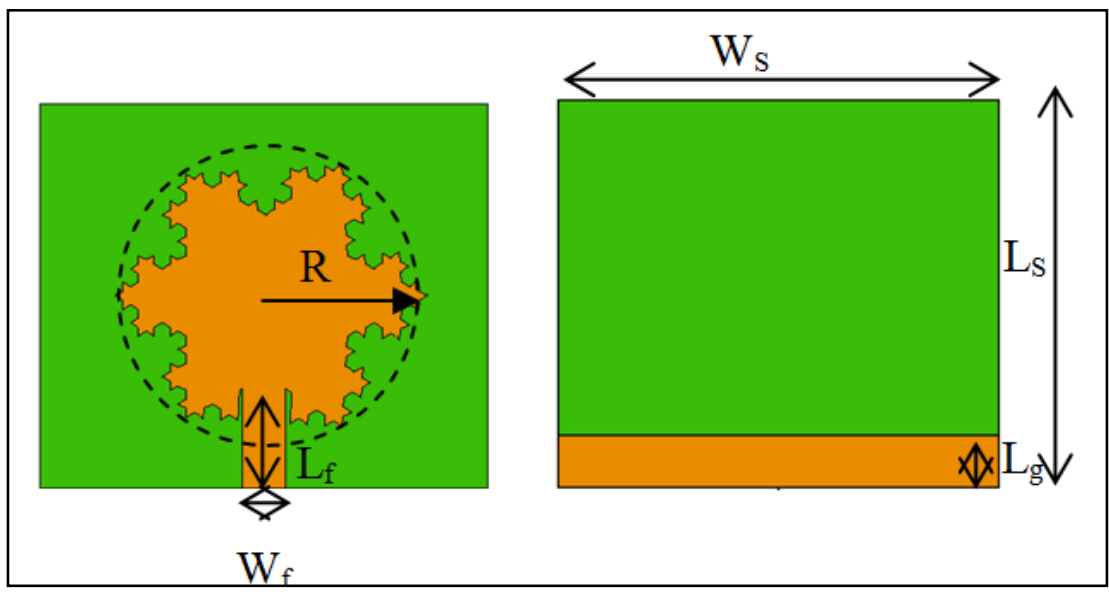

(a) the front face

(b) the back face

Figure1: The geometry of the CPW-Fed KOCH SNOWFLAKE Fractal Antenna

The characteristic impedance of a microstrip line $(\mathrm{Zm})$ is given by the formula (1) [15][18]

$$
\begin{aligned}
& \mathrm{Z}_{\mathrm{m}}=\frac{120 . \pi}{\sqrt{\varepsilon_{\mathrm{e}}}}\left[\frac{\mathrm{W}_{\mathrm{f}}}{\mathrm{H}}+1.393+0.667 \ln \left(\frac{\mathrm{W}_{\mathrm{f}}}{\mathrm{H}}+1.444\right)\right]^{-1} \\
& \text { And } \varepsilon_{\mathrm{e}}=\frac{1}{2}\left(\varepsilon_{\mathrm{r}}+1\right)+\frac{1}{2}\left(\varepsilon_{\mathrm{r}}-1\right)\left(1+12 \frac{\mathrm{H}}{\mathrm{W}_{\mathrm{f}}}\right)^{-\frac{1}{2}}
\end{aligned}
$$

With

$\varepsilon_{\mathrm{e}}$ : The effective permittivity

$\varepsilon_{\mathrm{r}}$ : The relative permittivity of the substrate

$\mathrm{H}$ : The thickness of the substrate

$W_{f:}$ the width of the microstrip line 
To adjust $Z_{m}=50 \Omega$, the value of $W f$ should be $3.35 \mathrm{~mm}$.

The other parameters are as follow: $\mathrm{mW}_{\mathrm{s}}=35 \mathrm{~mm}, \mathrm{~L}_{\mathrm{s}}=30 \mathrm{~mm}, \mathrm{~L}_{\mathrm{f}}=8 \mathrm{~mm}$, and $\mathrm{L}_{\mathrm{g}}=4 \mathrm{~mm}$

The generation of the KOCH SNOWFLAKE iterations is based on the triangle initiator and on the generator shown in the figure 2 .

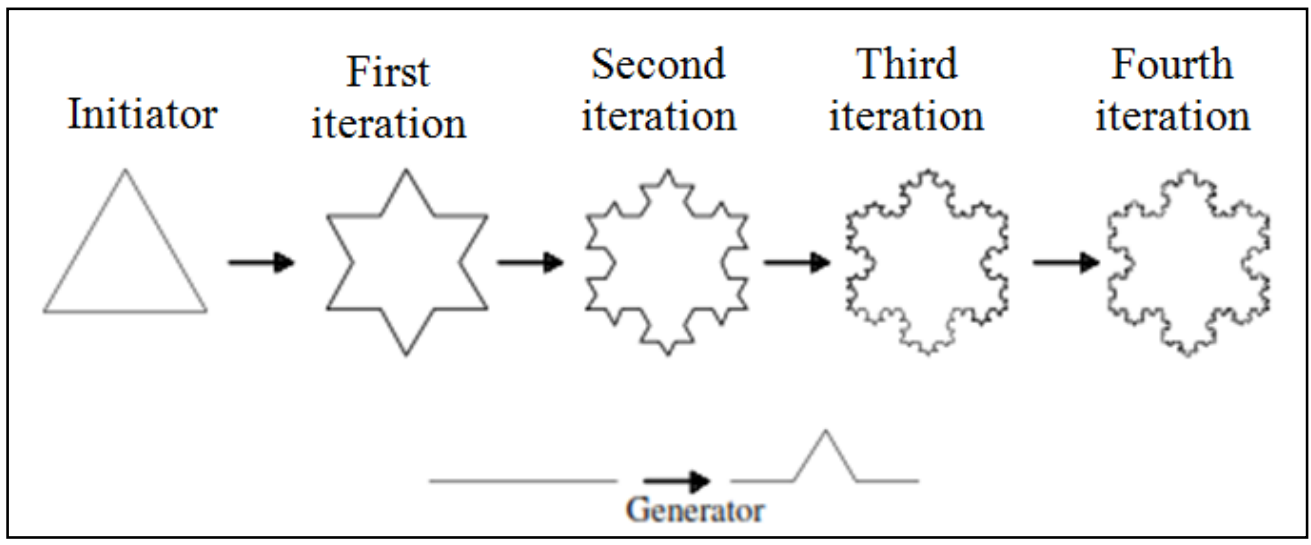

Figure2: The Four iterations of the KOCH SNOWFLAKE Fractal Antenna [20]

We observe that the radius of the fractal antenna $(R)$ is the same for all the iterations as shown in the figure3.

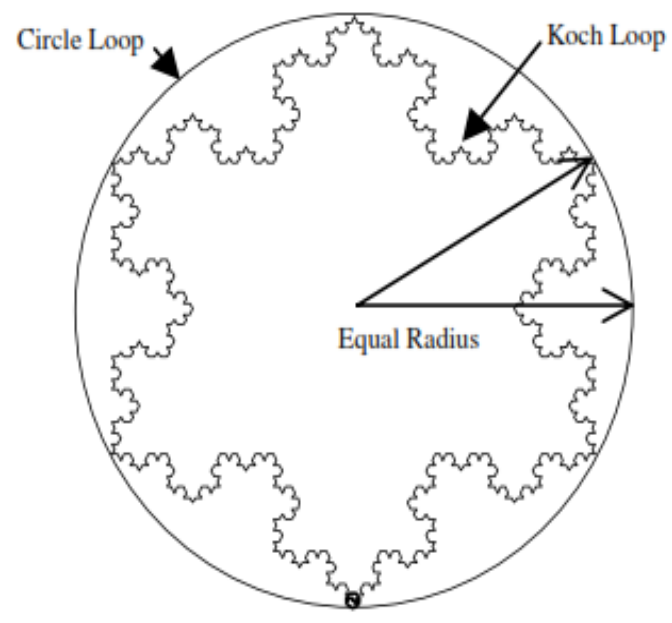

Figure 3: Circular and Koch loops of equal radii [21]

A parametric study is based on the variation of the parameters $R$.

\section{Results and Discussions}

\subsection{The initiator (iteration 0)}

For the initiator (figure 4), the variation of the simulated $S_{11}$ parameter versus the frequency for some values of $R$ is shown in the figure 5 . 


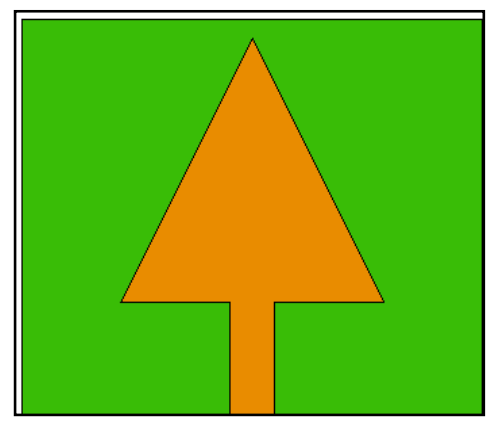

Figure 4: the front face of the antenna (the initiator)

We observe that, for $R=13 \mathrm{~mm}$, the antenna has 2 resonant frequencies $f_{r 1}=4.1 \mathrm{GHz}$ with $S_{11}=-$ $16.6 \mathrm{~dB}$ and $\mathrm{f}_{\mathrm{r} 2}=5 \mathrm{GHz}$ with $\mathrm{S}_{11}=-15.45 \mathrm{~dB}$. The bandwidth $(-10 \mathrm{~dB})$ of the antenna is $1.76 \mathrm{GHz}(3.5$ $-5.26 \mathrm{GHz})$.

For the $R=14 \mathrm{~mm}$, the antenna has 1 resonant frequency $f_{r 1}=4.4 \mathrm{GHz}$ with $S_{11}=-29.8 \mathrm{~dB}$. The bandwidth $(-10 \mathrm{~dB})$ of the antenna is $1.5 \mathrm{GHz}(3.5-5 \mathrm{GHz})$.

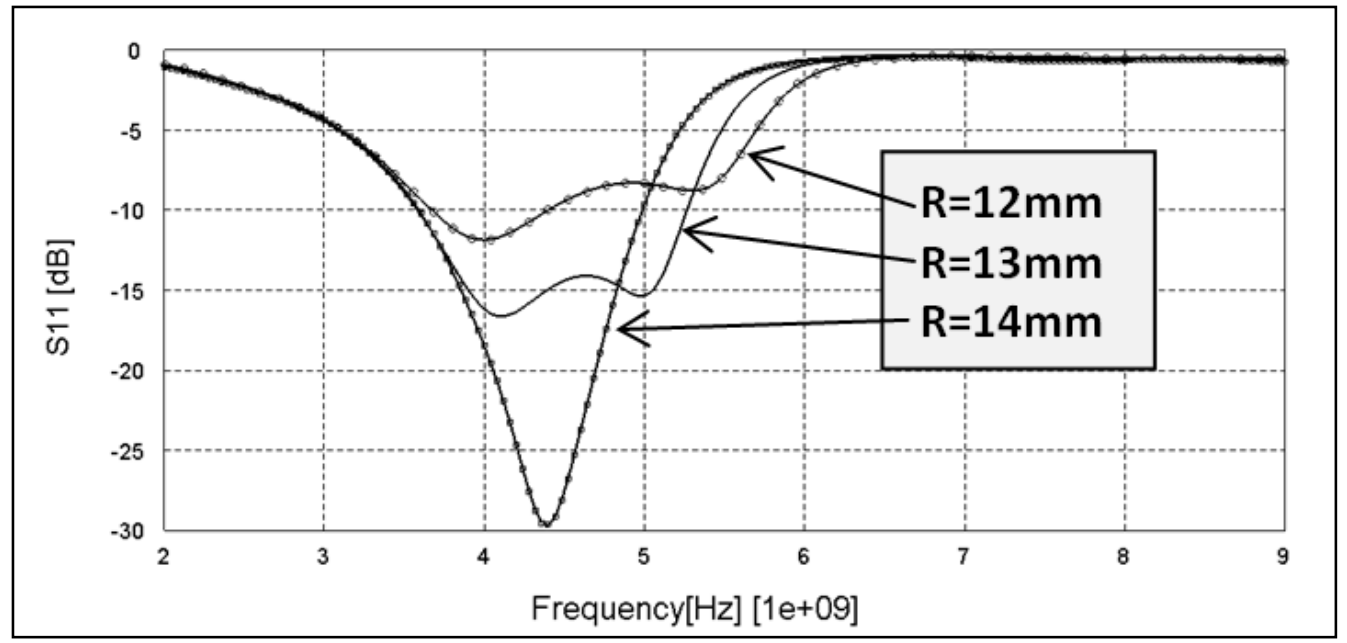

Figure5: Simulated $S_{11}$ versus frequency graph of the antenna (iteration0)

The figure 6 shows the evolution of the total maximum gain of the antenna versus the frequency for some values of the radius $R$. we observe that the gain increases when the frequency increases. The figure 7 shows an example for the $3 D$ total gain pattern of the antenna for $\mathrm{R}=14 \mathrm{~mm}$ and for the two frequencies $3.5 \mathrm{GHZ}$ and $5 \mathrm{GHZ}$. We observe that the shape of this pattern is nearly similar for the two frequencies. 


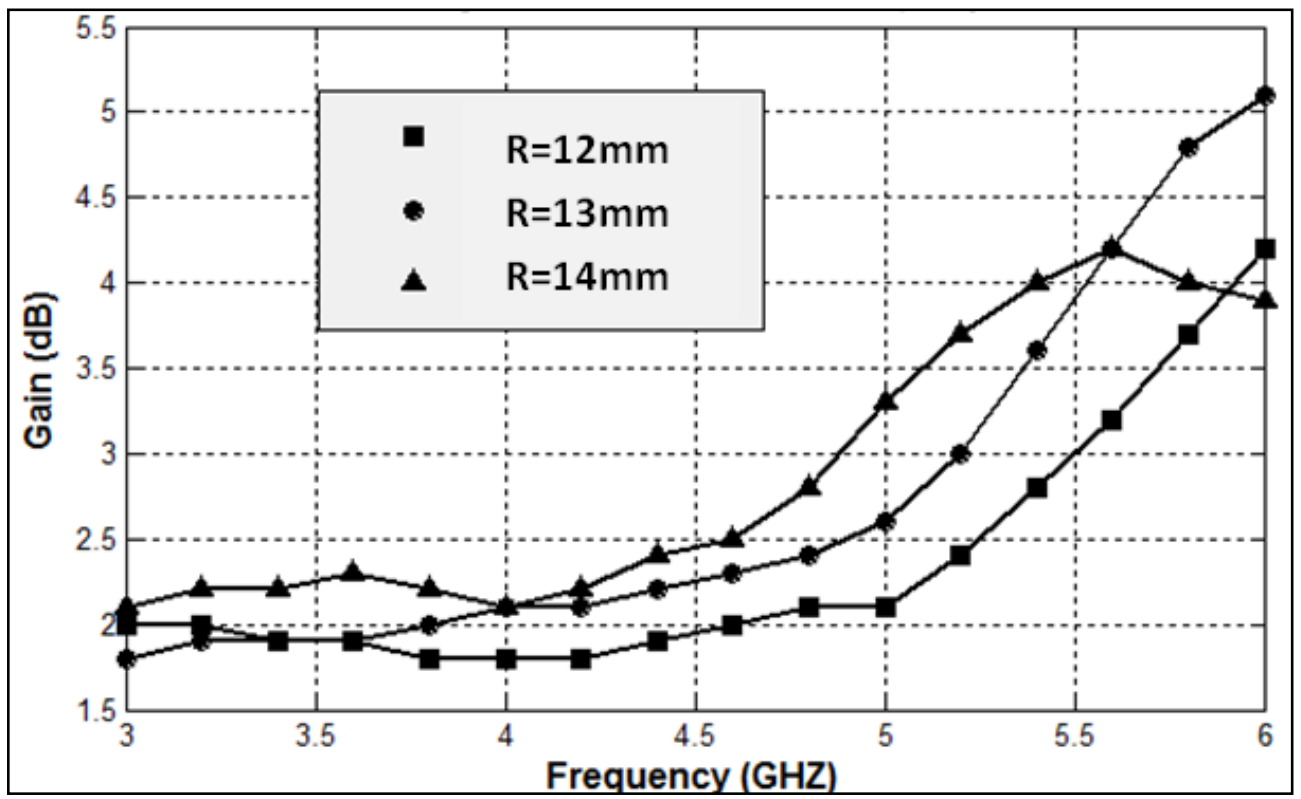

Figure6: Simulated Maximum Gain versus frequency graph of the antenna (iteration 0)

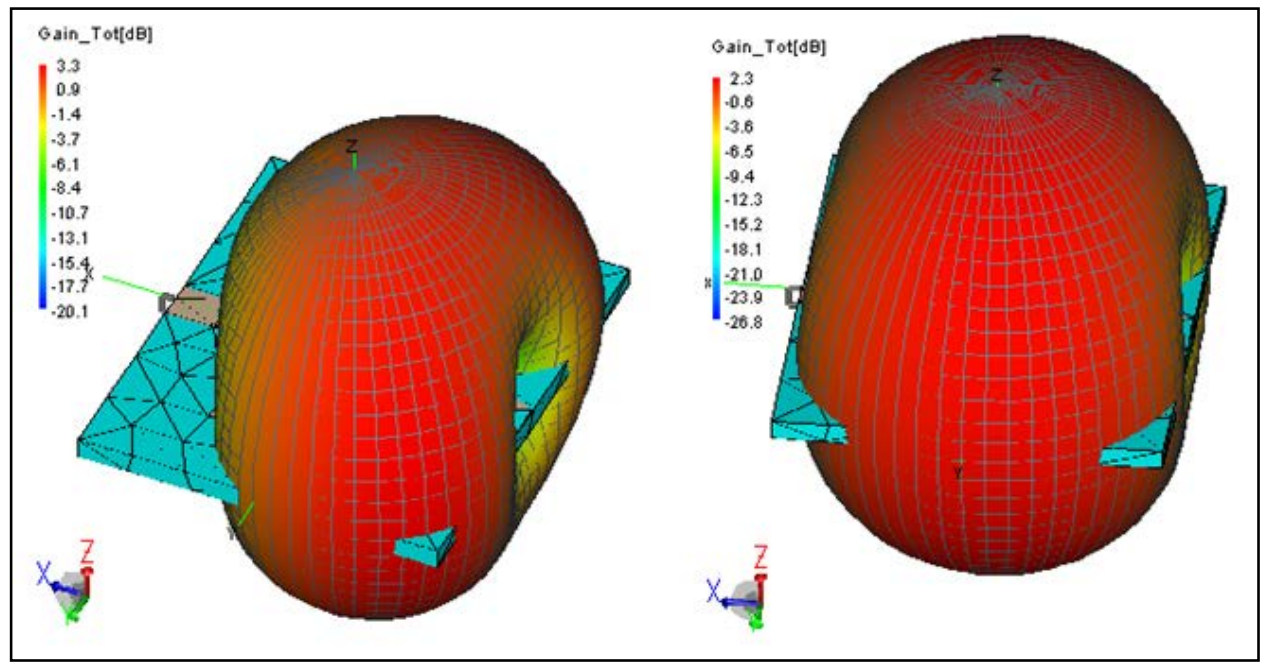

a) $F=5 G H Z$

(b) $\mathrm{F}=3.5 \mathrm{GHZ}$

Figure7: the 3D total gain of the antenna for $R=14 \mathrm{~mm}$

The table 1 summarizes the resonant frequencies, the bandwidths and the gains of the antenna in the Bandwidth.

Table 1: the bandwidths and the gains for the antenna (iteration 0)

\begin{tabular}{|c|c|l|l|l||}
\hline $\mathbf{R}(\mathbf{m m})$ & $\begin{array}{c}\text { Resonant frequencies } \\
(\mathbf{G H z})\end{array}$ & Bandwidth(-10dB) & $\mathbf{S}_{\mathbf{1 1}}{ }^{*}$ (dB) & Gain (dB) $^{* *}$ \\
\hline 12 & 4 & $750 \mathrm{MHz}(3.65-4.4)$ & -11.9 & 1.8 to 1.9 \\
\hline 13 & 4.1 and 5 & $1.76 \mathrm{GHz}(3.5-5.26)$ & -16.6 and 15.45 & 1.9 to 3.3 \\
\hline 14 & 4.4 & $1.5 \mathrm{GHz}(3.5-5)$ & -29.8 & 2.3 to 3.3 \\
\hline
\end{tabular}

$\left({ }^{*}\right)$ the $S_{11}$ are given in the resonant frequencies

$\left({ }^{* *}\right)$ the Gains are given in the bandwidth $(-10 \mathrm{~dB})$ 


\subsection{The First iteration}

For the first iteration (figure 8), the variation of the simulated $S_{11}$ parameter versus the frequency for some values of $R$ is shown in the figure 9 .

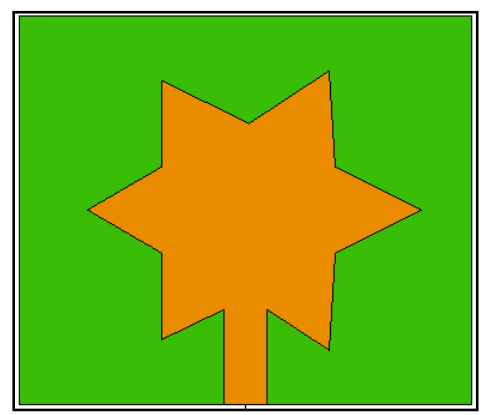

Figure 8: the front face of the antenna (First iteration)

We observe that, for $R=13 \mathrm{~mm}$, the antenna has 3 resonant frequencies $f_{r 1}=4.11 \mathrm{GHz}$ with $S_{11}=$ $-42 \mathrm{~dB}, \mathrm{f}_{\mathrm{r} 2}=5.4 \mathrm{GHz}$ with $\mathrm{S}_{11}=-16.4 \mathrm{~dB}$ and $\mathrm{f}_{\mathrm{r} 3}=6.7 \mathrm{GHz}$ with $\mathrm{S}_{11}=-16.16 \mathrm{~dB}$. The largest bandwidth of the antenna is $2.21 \mathrm{GHz}(3.56-5.77 \mathrm{GHz})$.

For the $R=14 \mathrm{~mm}$, the antenna has 3 resonant frequencies $\mathrm{f}_{\mathrm{r} 1}=4.04 \mathrm{GHz}$ with $\mathrm{S}_{11}=-15.7 \mathrm{~dB}, \mathrm{f}_{\mathrm{r} 2}=$ 5.4GHZ with $S_{11}=-39.25 \mathrm{~dB}$ and $\mathrm{f}_{\mathrm{r} 3}=6.4 \mathrm{GHZ}$ with $\mathrm{S}_{11}=-17.58 \mathrm{~dB}$. The largest bandwidth of the antenna is $2.2 \mathrm{GHz}(3.6-5.8 \mathrm{GHz})$.

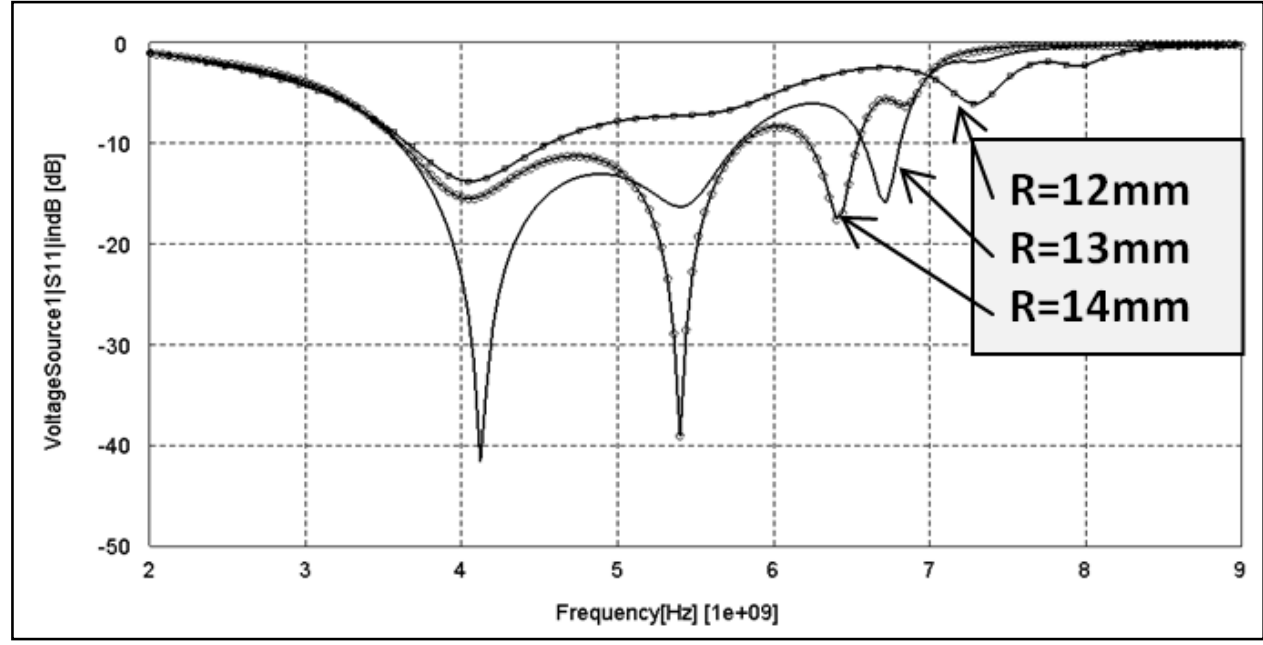

Figure9: Simulated $S_{11}$ versus frequency graph of the antenna (First iteration)

The figure 10 shows the evolution of the maximum total gain of the antenna versus the frequency for some values of the radius $R$. we observe that the gain increases when the frequency increases. We observe also that the gain increases when the $\mathrm{R}$ increase. The figure 10 shows an example for the $3 \mathrm{D}$ total gain pattern of the antenna for $\mathrm{R}=14 \mathrm{~mm}$ and for the two frequencies $4 \mathrm{GHZ}$ and $5.4 \mathrm{GHZ}$. We observe that the shape of this pattern is nearly similar for the two frequencies. 


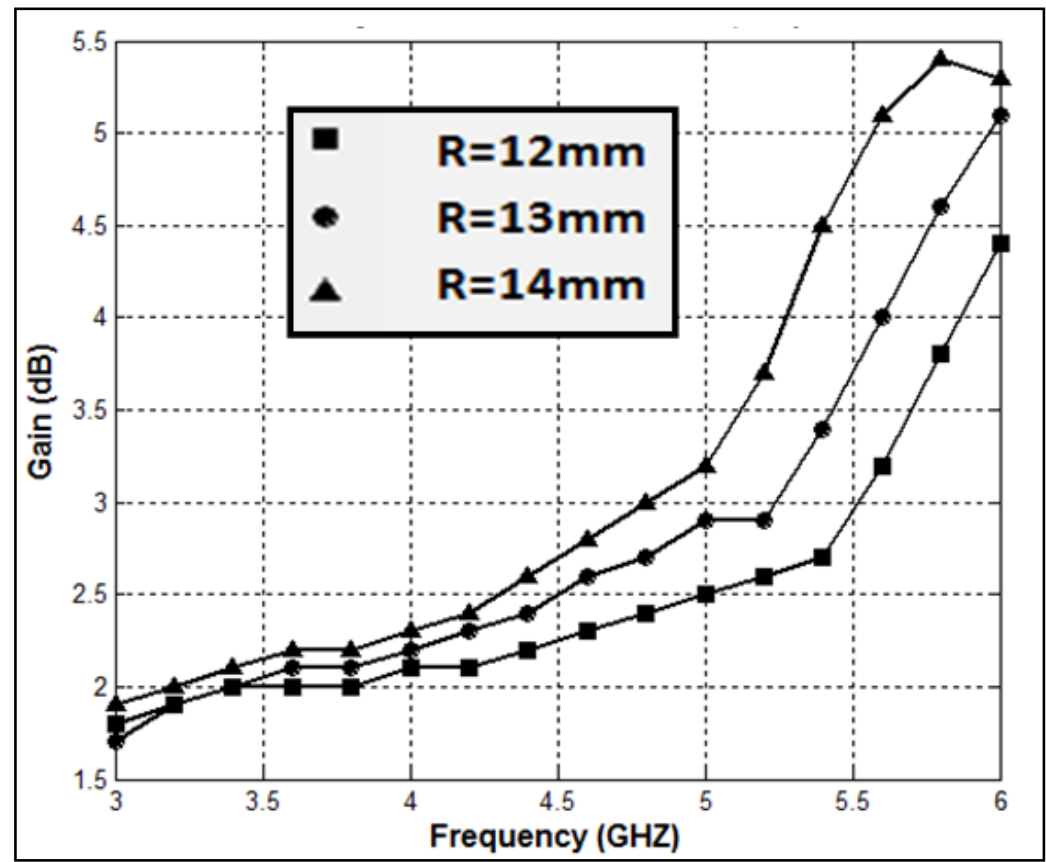

Figure10: Simulated Gain versus frequency graph of the antenna (iteration 1)

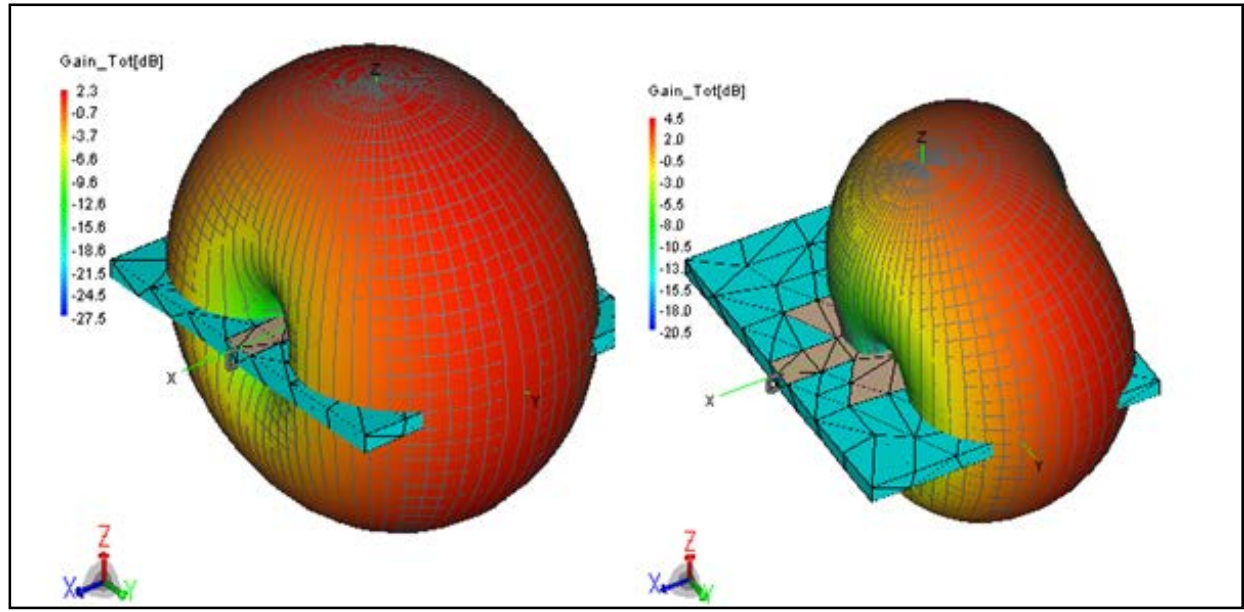

(a) $\mathrm{F}=4 \mathrm{GHz}$

(b) $\mathrm{F}=5.4 \mathrm{GHz}$

Figure11: the 3D total gain of the antenna for $R=14 \mathrm{~mm}$

The table 2 summarizes the resonant frequencies, the bandwidths and the gains of the antenna in the Bandwidth. 


\begin{tabular}{|c|c|c|c|c|}
\hline$R(\mathrm{~mm})$ & $\begin{array}{l}\text { Resonant frequencies } \\
(\mathrm{GHz})\end{array}$ & $\begin{array}{l}\text { Bandwidth } \\
\text { (-10dB) }\end{array}$ & $\mathrm{S}_{11}{ }^{*}(\mathrm{~dB})$ & Gain (dB) \\
\hline 12 & 4.05 & $\begin{array}{l}930 \mathrm{MHz} \\
(3.64-4.57)\end{array}$ & -13.84 & 2 to 2.3 \\
\hline 13 & $\begin{array}{l}4.11 \text { and } 5.4 \text { and } \\
6.7\end{array}$ & $\begin{array}{l}2.21 \mathrm{GHz} \\
(3.56-5.77) \\
\text { And } 210 \mathrm{MHz}(6.59- \\
6.8)\end{array}$ & $\begin{array}{l}-42 \text { and } \\
-16.4 \text { and }-16.16\end{array}$ & $\begin{array}{l}2.1 \text { to } 4.5 \\
\text { And } \\
5.5 \text { to } 5.7\end{array}$ \\
\hline 14 & $\begin{array}{l}4.04 \text { and } \\
5.4 \text { and } \\
6.4\end{array}$ & $\begin{array}{l}2.2 \mathrm{GHz} \\
(3.6-5.8) \\
\text { And } \\
310 \mathrm{MHz}(6.21-6.52)\end{array}$ & $\begin{array}{l}-15.7 \text { and } \\
-39.25 \text { and } \\
-17.58\end{array}$ & $\begin{array}{l}2.2 \text { to } 5.4 \\
\text { And } \\
5.4 \text { to } 5.6\end{array}$ \\
\hline
\end{tabular}

Table 2: the bandwidths and the gains for the antenna (First iteration)

$\left({ }^{*}\right)$ the $S_{11}$ are given in the resonant frequencies

$\left({ }^{* *}\right)$ the Gains are given in the bandwidth

\subsection{The Second iteration}

For the second iteration (figure 12), the variation of the simulated $S_{11}$ parameter versus the frequency for some values of $R$ is shown in the figure 13.

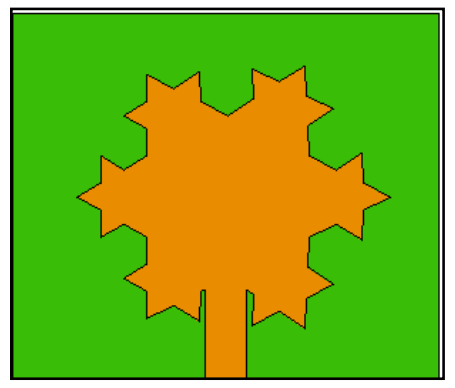

Figure 12: the front face of the antenna (Second iteration)

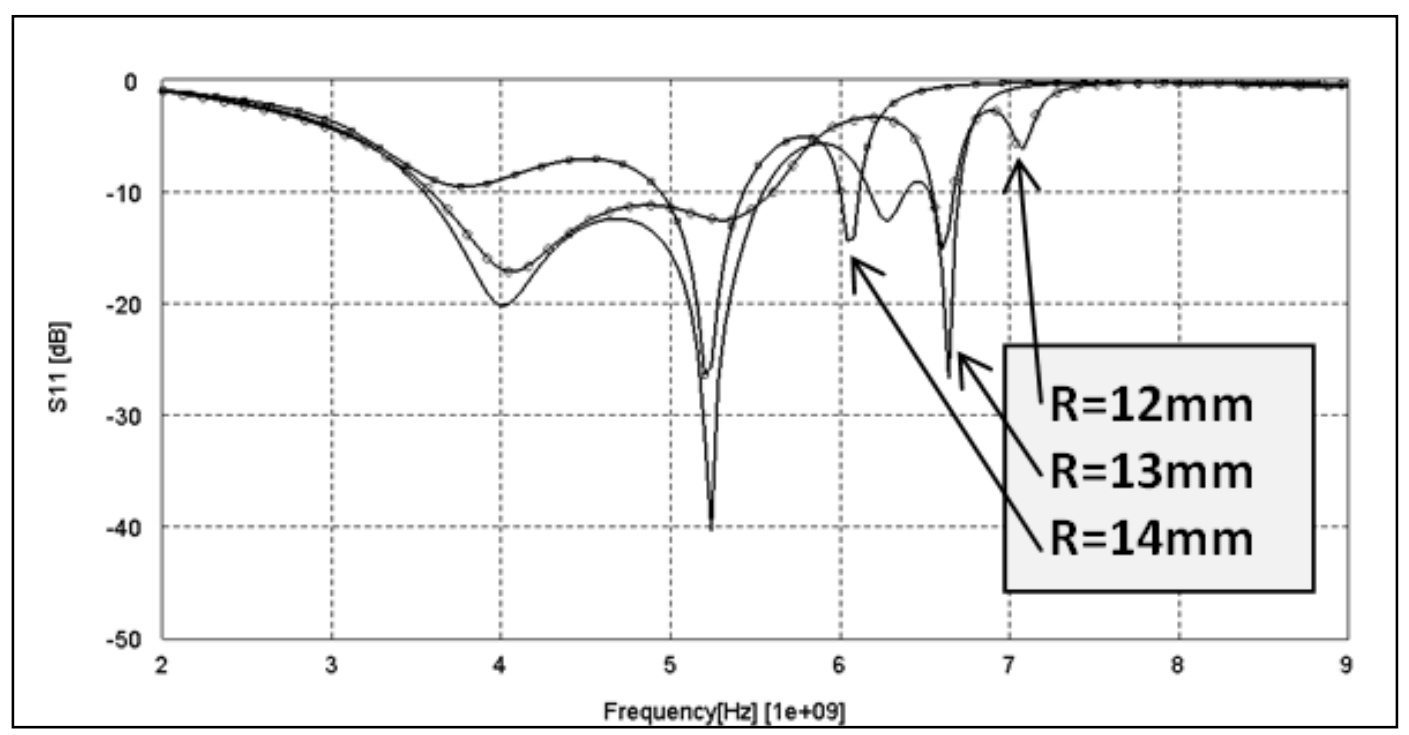


We observe that, for $R=13 \mathrm{~mm}$, the antenna has 4 resonant frequencies $f_{r 1}=4 G H z$ with $S_{11}=$ $20.4 \mathrm{~dB}, \mathrm{f}_{\mathrm{r} 2}=5.23 \mathrm{GHz}$ with $\mathrm{S}_{11}=-40.3 \mathrm{~dB}, \mathrm{f}_{\mathrm{r} 3}=6.27 \mathrm{GHz}$ with $\mathrm{S}_{11}=-12.55 \mathrm{~dB}$, and $\mathrm{f}_{\mathrm{r} 4}=6.64 \mathrm{GHz}$ with $\mathrm{S}_{11}=-27 \mathrm{~dB}$. The largest bandwidth of the antenna is $2.02 \mathrm{GHZ}(3.53-5.55 \mathrm{GHz})$.

For the $R=12 \mathrm{~mm}$, the antenna has 3 resonant frequencies $f_{r 1}=4.07 \mathrm{GHz}$ with $S_{11}=-17.24 \mathrm{~dB}, \mathrm{f}_{\mathrm{r} 2}=$ $5.32 \mathrm{GHz}$ with $\mathrm{S}_{11}=-12.64$, and $\mathrm{f}_{\mathrm{r} 3}=6.6 \mathrm{GHz}$ with $\mathrm{S}_{11}=-15.3 \mathrm{~dB}$. The largest bandwidth of the antenna is $2.02 \mathrm{GHz}(3.57-5.59 \mathrm{GHz})$.

For the $R=14 \mathrm{~mm}$, the antenna has 2 resonant frequencies $f_{r 1}=5.2 \mathrm{GHz}$ with $S_{11}=-26.55 \mathrm{~dB}$, and $f_{r 2}=6.07 \mathrm{GHz}$ with $S_{11}=-14.3 \mathrm{~dB}$, and $\mathrm{fr} 3=6.6 \mathrm{GHz}$ with $\mathrm{S}_{11}=-15.3 \mathrm{~dB}$. The largest bandwidth of the antenna is $460 \mathrm{MHz}(4.95-5.41 \mathrm{GHz})$.

The figure 14 shows the evolution of the gain of the antenna versus the frequency for some values of the radius $R$. we observe that the gain increases when the frequency increases. We observe also that in general, the gain increases when the $R$ increases. The figure 15 shows an example for the 3D total gain pattern of the antenna for $\mathrm{R}=13 \mathrm{~mm}$ and for the two frequencies $4 \mathrm{GHz}$ and $5.2 \mathrm{GHz}$. We observe that the shape of this pattern is nearly similar for the two frequencies.

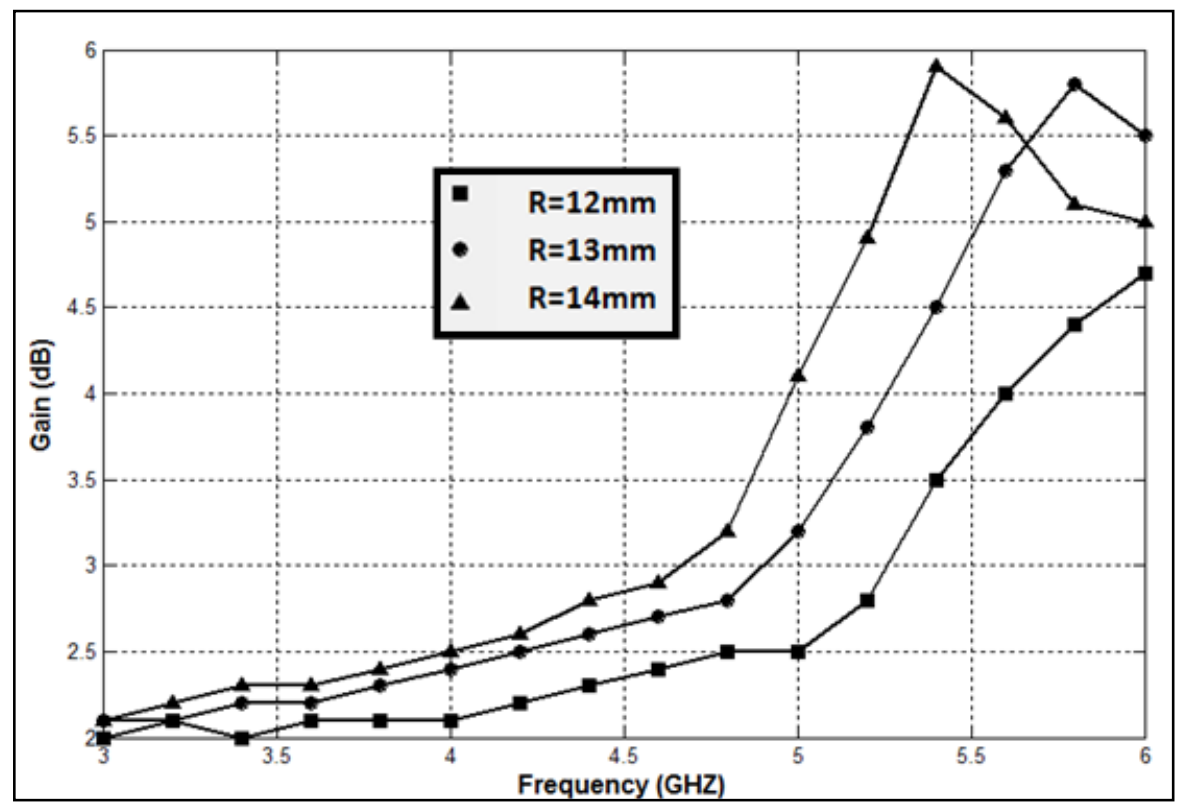

Figure14: Simulated Gain versus frequency graph of the antenna (iteration 2) 


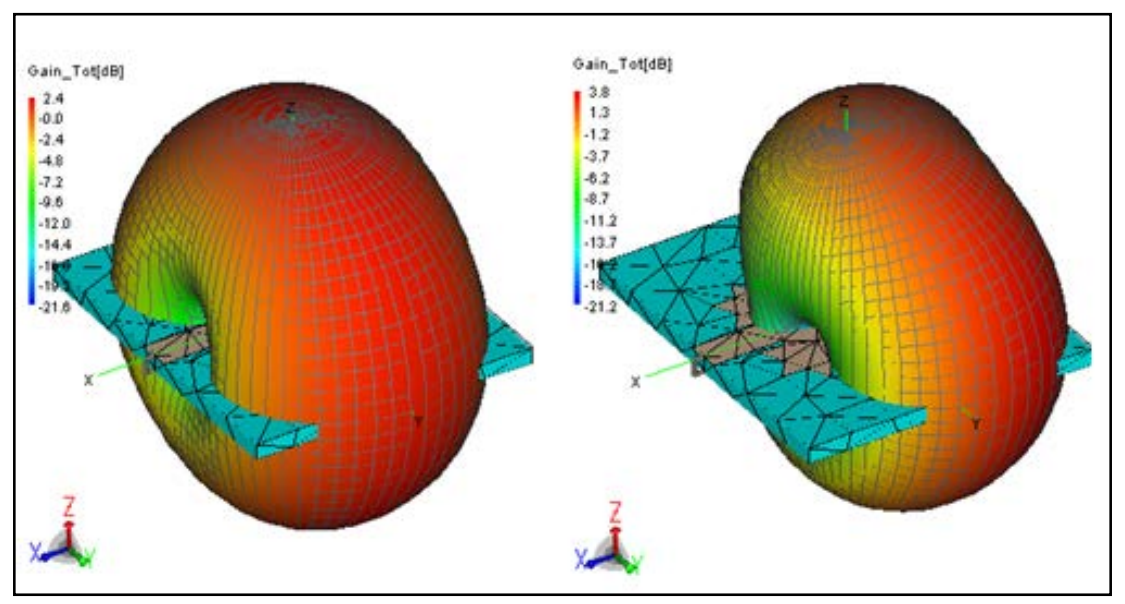

(a) $\mathrm{F}=4 \mathrm{GHZ}$

(b) $\mathrm{F}=5.2 \mathrm{GHZ}$

Figure15: the 3D total gain of the antenna for $R=13 \mathrm{~mm}$

The table 3 summarizes the resonant frequencies, the bandwidths and the gains of the antenna in the Bandwidth.

Table 3: the bandwidths and the gains for the antenna (First iteration)

\begin{tabular}{|c|c|c|c|c|}
\hline $\mathrm{R}(\mathrm{mm})$ & $\begin{array}{l}\text { Resonant } \\
\text { frequencies (GHZ) }\end{array}$ & Bandwidth (-10dB) & $S_{11}{ }^{*}(d B)$ & Gain (dB) \\
\hline 12 & $\begin{array}{l}4.07 \text { and } \\
5.32 \text { and } \\
6.6\end{array}$ & $2.02 \mathrm{GHZ} \quad(3.57-5.59)$ & $\begin{array}{l}-17.24 \text { and } \\
-12.64 \text { and } \\
-15.3\end{array}$ & $\begin{array}{l}2.1 \text { to } 4 \\
\text { And } \\
5.3 \text { to } 4.9\end{array}$ \\
\hline 13 & $\begin{array}{l}4 \text { and } \\
5.23 \text { and } \\
6.27 \text { and } 6.64\end{array}$ & $\begin{array}{l}2.02 \mathrm{GHZ}(3.53-5.55) \\
\text { And } 240 \mathrm{MHZ}(6.16-6.4) \\
\text { And 180MHZ }(6.52-6.7)\end{array}$ & $\begin{array}{l}-20.4 \text { and } \\
-40.3 \text { and } \\
-12.55 \text { and } \\
-27\end{array}$ & $\begin{array}{l}2.2 \text { to } 5.1 \\
\text { And } \\
4.9 \text { to } 4.1 \\
\text { And } \\
4.7 \text { to } 5.1\end{array}$ \\
\hline 14 & $\begin{array}{l}5.2 \text { and } \\
6.07\end{array}$ & $\begin{array}{l}460 \mathrm{MHZ}(4.95-5.41) \\
\text { And } \\
120 \mathrm{MHZ}(5.99-6.11)\end{array}$ & $\begin{array}{l}-26.55 \text { and } \\
-14.3\end{array}$ & $\begin{array}{l}3.9 \text { to } 5.6 \\
\text { And } \\
4.2 \text { to } 5\end{array}$ \\
\hline
\end{tabular}

$(*)$ the $S_{11}$ are given in the resonant frequencies

$\left({ }^{* *}\right)$ the Gains are given in the bandwidth

\subsection{The Third iteration}

For the third iteration (figure 16), the variation of the simulated $S_{11}$ parameter versus the frequency for some values of $R$ is shown in the figure 17. 


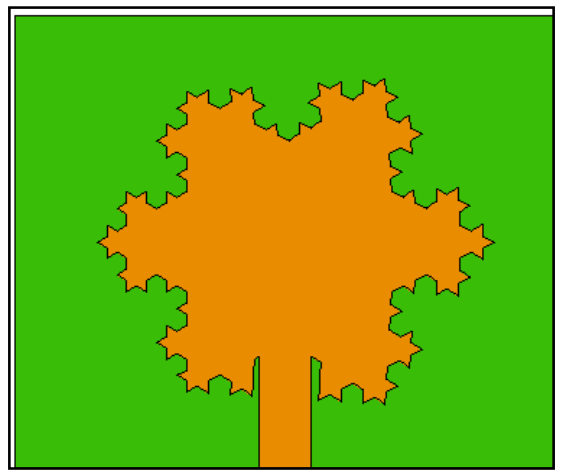

Figure 16: the front face of the antenna (Third iteration)

We observe that, for $R=13 \mathrm{~mm}$, the antenna has 3 resonant frequencies $f_{r 1}=3.9 \mathrm{GHz}$ with $S_{11}=-$ $17.67 \mathrm{~dB}, \mathrm{f}_{\mathrm{r} 2}=5.08 \mathrm{GHz}$ with $\mathrm{S}_{11}=-21.45 \mathrm{~dB}$, and $\mathrm{f}_{\mathrm{r} 3}=5.92 \mathrm{GHz}$ with $\mathrm{S}_{11}=-13.31$. The largest bandwidth of the antenna is $1.89 \mathrm{GHz}(3.46-5.35 \mathrm{GHz})$.

For the $R=12 \mathrm{~mm}$, the antenna has 3 resonant frequencies $f_{r 1}=4 G H z$ with $S_{11}=-19 d B, \quad f_{r 2}=$ $5.2 \mathrm{GHz}$ with $\mathrm{S}_{11}=-16.4$, and $\mathrm{f}_{\mathrm{r} 3}=7 \mathrm{GHz}$ with $\mathrm{S}_{11}=-18.5$. The largest bandwidth of the antenna is $2 \mathrm{GHz}(3.49-5.49 \mathrm{GHz})$.

For the $R=14 \mathrm{~mm}$, the antenna has 2 resonant frequencies $f r 1=5.03 \mathrm{GHz}$ with $\mathrm{S}_{11}=-35.8 \mathrm{~dB}$, and $\mathrm{fr} 2=5.73 \mathrm{GHz}$ with $\mathrm{S}_{11}=-23.7 \mathrm{~dB}$. The largest bandwidth of the antenna is $460 \mathrm{MHz}(4.74-5.2$ $\mathrm{GHz}$ ).

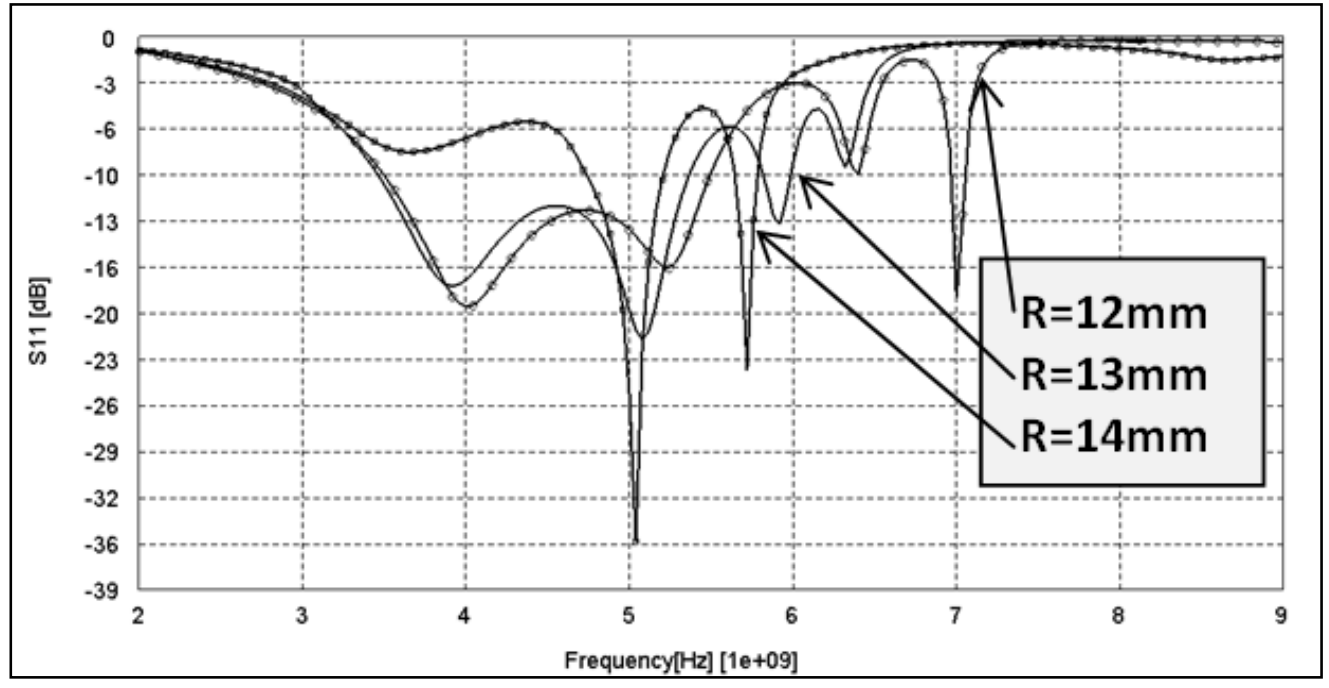

Figure17: Simulated $S_{11}$ versus frequency graph of the antenna (Third iteration)

The figure 18 shows the evolution of the gain of the antenna versus the frequency for some values of the radius $R$. we observe in general, that the gain increases when the frequency increases. We observe also that in general, the gain increases when the $\mathrm{R}$ increases. The figure 19 shows an example for the 3D total gain pattern of the antenna for $R=13 \mathrm{~mm}$ and for the two frequencies $4 \mathrm{GHz}$ and $5 \mathrm{GHz}$. 


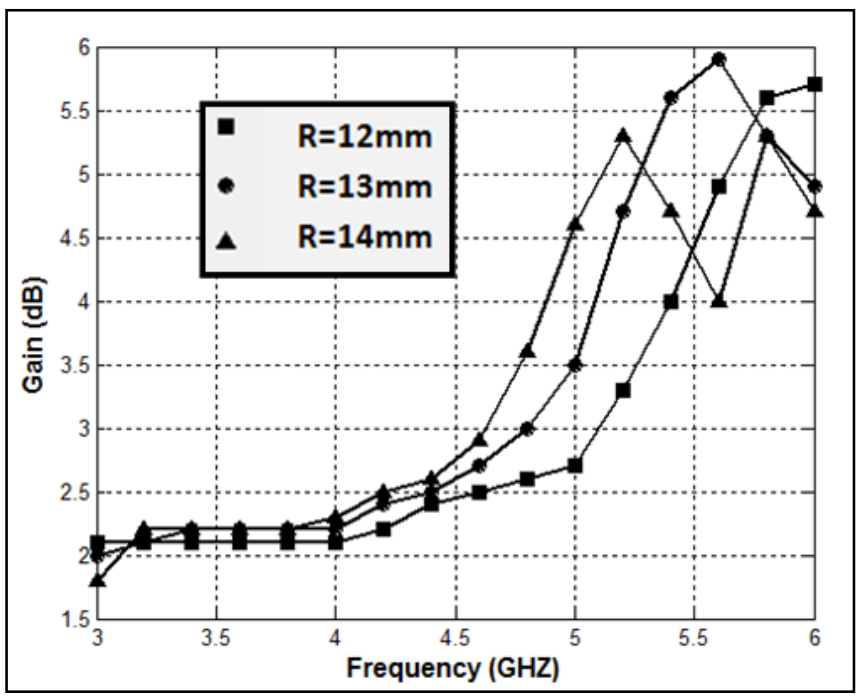

Figure 18: Simulated Gain versus frequency graph of the antenna (iteration 3)

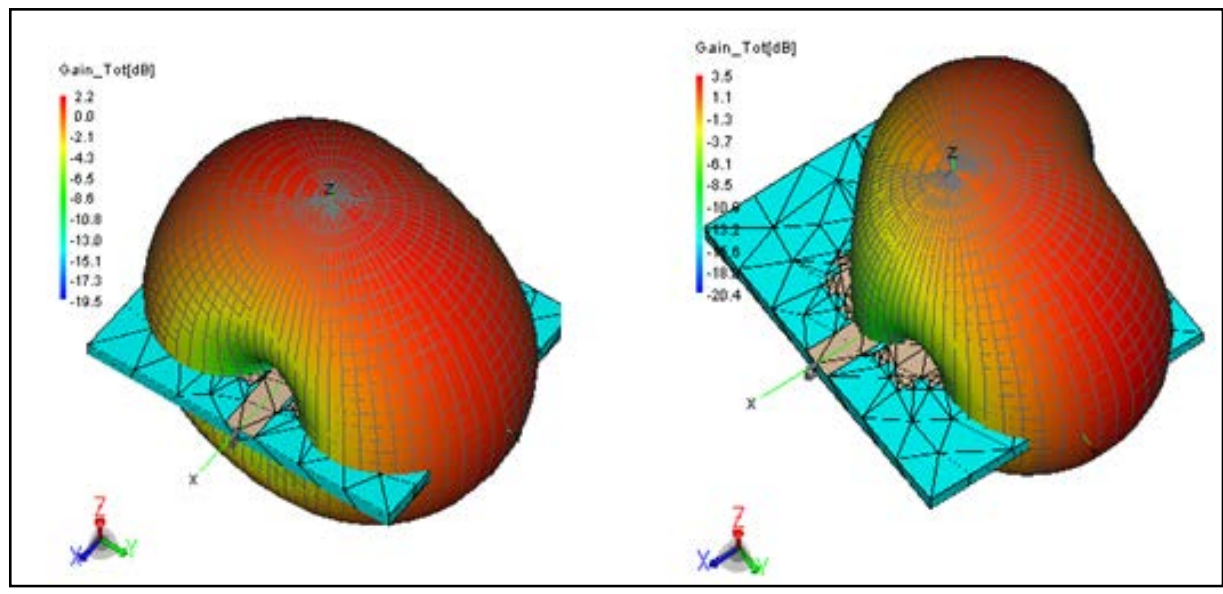

(a) $\mathrm{F}=4 \mathrm{GHZ}$

(b) $F=5 G H Z$

Figure19: the 3D total gain of the antenna for $R=13 \mathrm{~mm}$

The table 4 summarizes the resonant frequencies, the bandwidths and the gains of the antenna in the Bandwidth.

Table 4: the bandwidths and the gains for the antenna (First iteration)

\begin{tabular}{|c|c|c|c|c|}
\hline$R(\mathrm{~mm})$ & $\begin{array}{l}\text { Resonant frequencies } \\
(\mathrm{GHz})\end{array}$ & Bandwidth (-10dB) & $S_{11}{ }^{*}(d B)$ & Gain (dB) \\
\hline 12 & $\begin{array}{l}4 \text { and } \\
5.2 \text { and } 7\end{array}$ & $\begin{array}{l}2 \mathrm{GHz} \quad(3.49-5.49) \\
\text { And } 90 \mathrm{MHZ}(6.96-7.05)\end{array}$ & $\begin{array}{l}-19 \text { and } \\
-16.4 \text { and }-18.5\end{array}$ & $\begin{array}{l}2.1 \text { to } 4.4 \\
\text { And } 6.4 \text { to } 6.2\end{array}$ \\
\hline 13 & $\begin{array}{l}.9 \text { and } \\
5.08 \text { and } 5.92\end{array}$ & $\begin{array}{l}1.89 \mathrm{GHz}(3.46-5.35) \\
\text { And } 190 \mathrm{MHz}(5.8-5.99)\end{array}$ & $\begin{array}{l}-17.67 \text { and } \\
-21.45 \text { and }-13.31 \\
\end{array}$ & $\begin{array}{l}2.2 \text { to } 5.5 \\
\text { And } 5.3 \text { to } 4.9 \\
\end{array}$ \\
\hline 14 & $\begin{array}{l}5.03 \text { and } \\
5.73\end{array}$ & $\begin{array}{l}460 \mathrm{MHz}(4.74-5.2) \\
\text { And } \\
200 \mathrm{MHz}(5.6-5.8)\end{array}$ & $\begin{array}{l}-35.8 \text { and } \\
-23.4\end{array}$ & $\begin{array}{l}3.2 \text { to } 5.3 \\
\text { And } \\
4 \text { to } 5.3\end{array}$ \\
\hline
\end{tabular}

$\left({ }^{*}\right)$ the $\mathrm{S}_{11}$ are given in the resonant frequencies

$(* *)$ the Gains are given in the bandwidth 


\subsection{The effect of the iterations}

For all the values of the radius $\mathrm{R}$, we observe that in general, the maximum total gain of the antenna increase by increasing the number of iterations (Figure 20). We observe also that in general, the number of the resonant frequencies and the bandwidth increase when the number of iterations increase (figure 21)

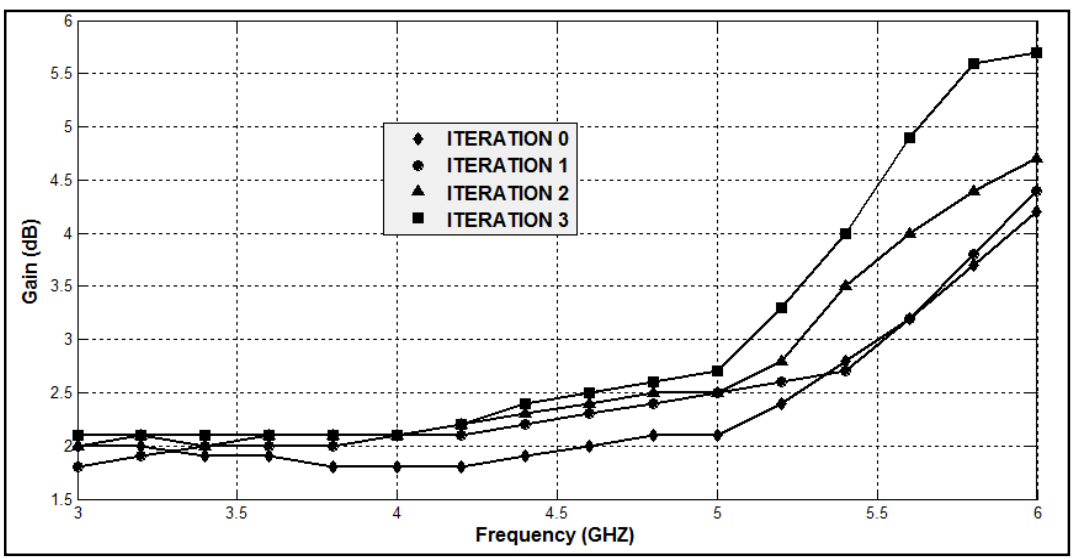

(a) $\mathrm{R}=12 \mathrm{~mm}$

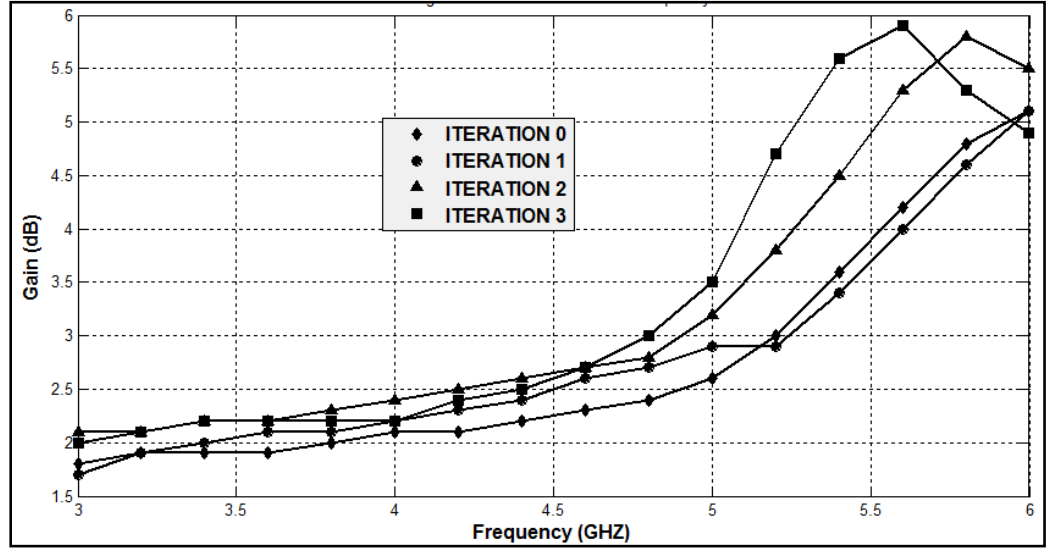

(b) $\mathrm{R}=13 \mathrm{~mm}$

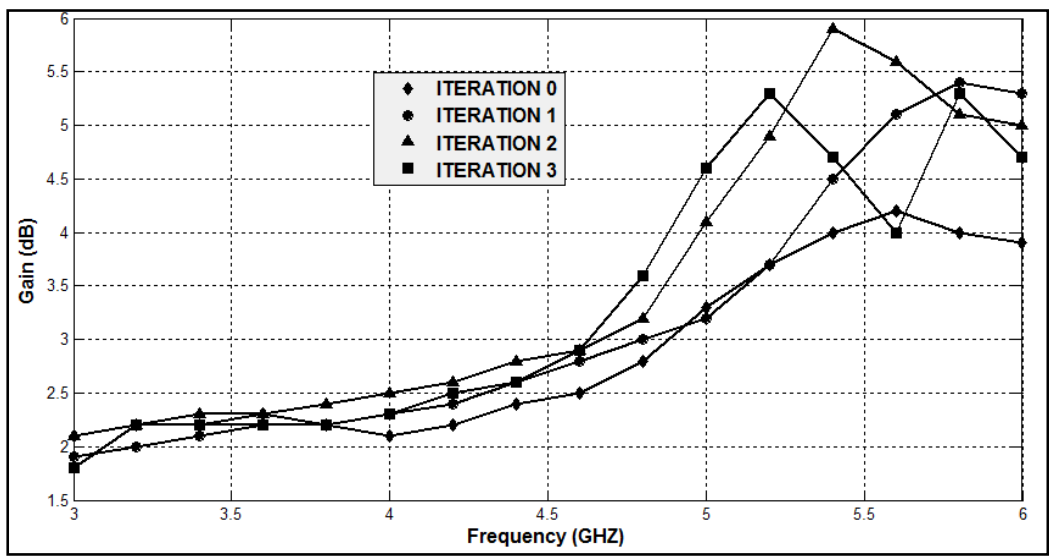

(c) $\mathrm{R}=14 \mathrm{~mm}$

Figure20: Simulated Gain versus frequency graph of the antenna and versus the number of iterations 


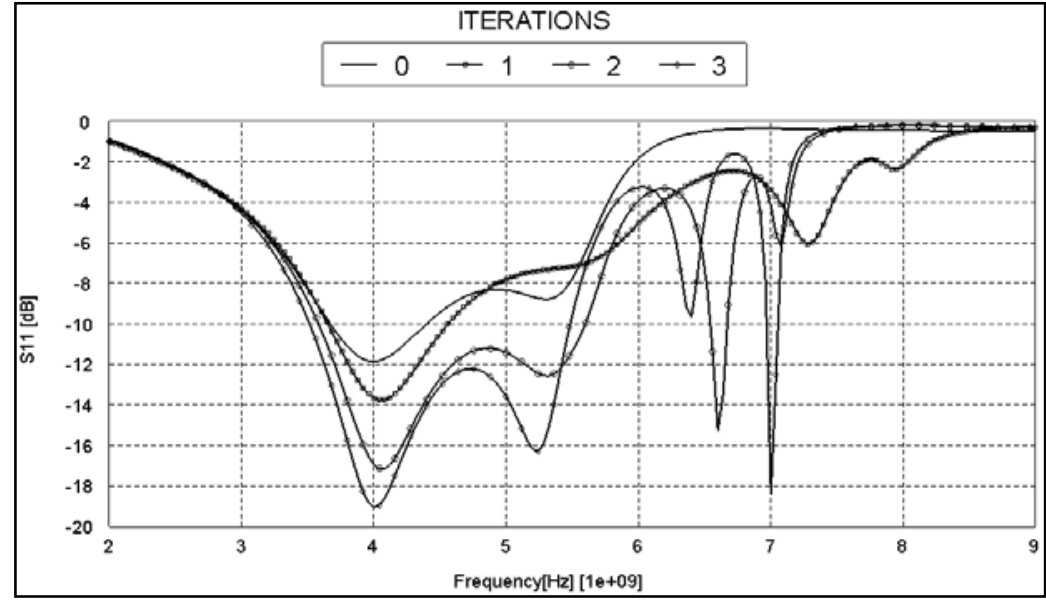

(a) $R=12 \mathrm{~mm}$

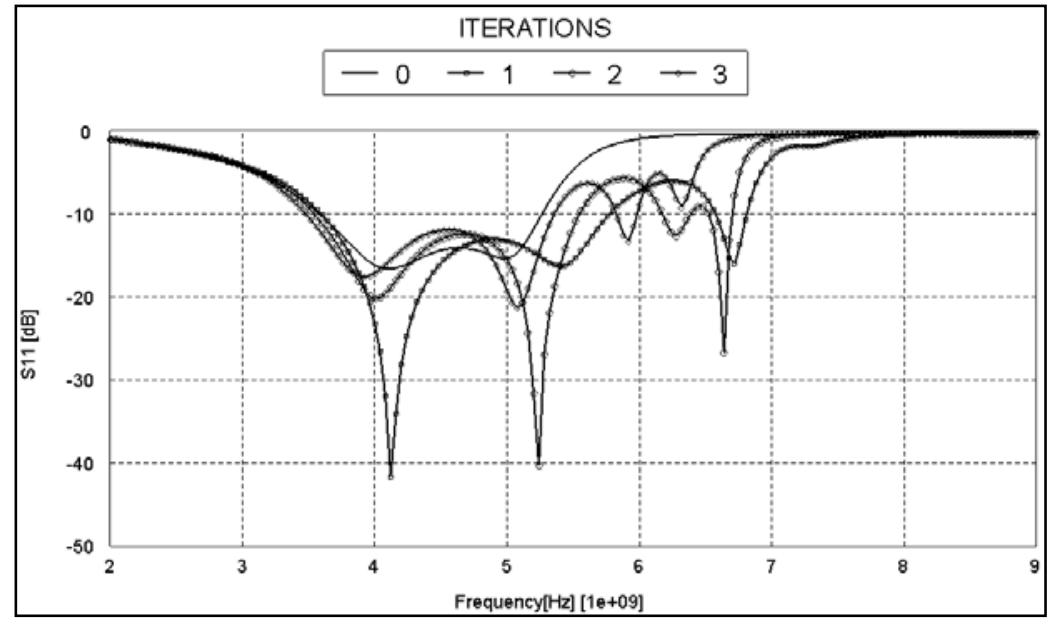

(b) $R=13 \mathrm{~mm}$

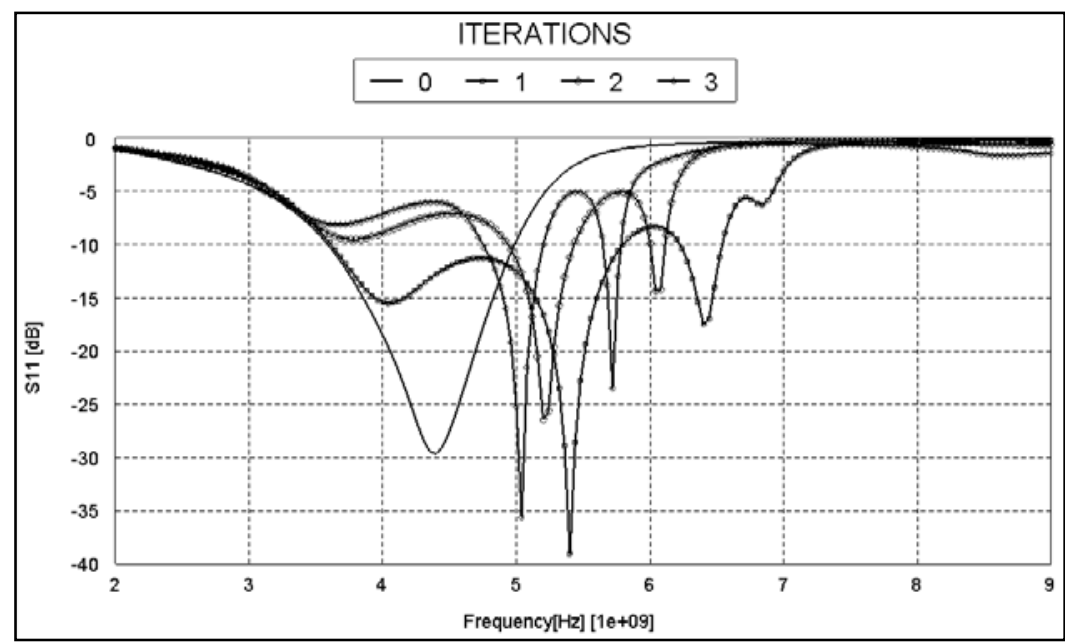

(c) $\mathrm{R}=13 \mathrm{~mm}$

Figure21: Simulated $S_{11}$ versus frequency graph of the antenna for the 4 iterations 


\section{Conclusion}

The fractal concept is a one of the better solutions to design a simple, low profile and miniaturized antennas, the use of the CPW-Fed technique increases the bandwidth of the antennas and it is very easy to manufacture.

The CPW-Fed KOCH SNOWFLAKE Fractal antenna is a good solution for the UWB applications. Increasing the number of iteration allows obtaining a low profile antenna with good performances, operating for many UWB-applications.

For some configurations of the proposed structures, the antennas are a good solution for the 3.7-4.2GHz C-Band, 5.15-5.82GHz WLAN, and 5GHz WIMAX applications.

Also, further dimensions and iterations can be done to obtain antennas with another sizes, more Ultra Wide Bands and better antenna performances.

\section{REFERENCES}

[1]. Aidin Mehdipour, Christopher W. Trueman, Compact Multiband Planar Antenna for 2.4/3.5/5.2/5.8-GHz Wireless Applications, IEEE IEEE Antennas and Wireless Propagation Letters, Vol. 11, 2012, pp 144-147.

[2]. Ming Chen, Chi-Chih Chen, A Compact Dual-Band GPS Antenna Design, IEEE IEEE Antennas and Wireless Propagation Letters, Vol. 12, 2013, pp 245-248.

[3]. Chitra Varadhan, Jayaram Kizhekke Pakkathillam, Malathi Kanagasabai, Ramprabhu Sivasamy, Rajesh Natarajan, and Sandeep Kumar Palaniswamy, Triband Antenna Structures for RFID Systems Deploying Fractal Geometry, IEEE IEEE Antennas and Wireless Propagation Letters, Vol. 12, 2013, pp 437-440

[4]. Cheng Zhou, Guangming Wang, Yawei Wang, Binfeng Zong, and Jing Ma, CPW-Fed Dual-Band Linearly and Circularly Polarized Antenna Employing Novel Composite Right/Left-Handed Transmission-Line, IEEE Antennas and Wireless Propagation Letters, Vol. 12, 2013, pp 1073-1076

[5]. Xu Liqin, Zhong Jin, Wang Chonghua, A Novel Microstrip Antenna with Double Notches, International Conference on Advanced Information Engineering and Education Science (ICAIEES 2013), pp. 44-46

[6]. Moeikham, P, Mahatthanajatuphat, C. ; Akkaraekthalin, P, "A compact ultrawideband monopole antenna with V-shaped slit for $5.5 \mathrm{GHz}$ notched band" , Electrical Engineering/Electronics, Computer, Telecommunications and Information Technology (ECTI-CON), 2012 9th International Conference on 1618 May 2012, pp. 1-4

[7]. Raj Kumar, K. K. Sawant, "On the Design of Circular Fractal Antenna with U-Shape Slot in CPW-Feed", Wireless Engineering and Technology, Vol.1 No.2, 2010, pp. 81-87. doi: 10.4236/wet.2010.12012.

[8]. Y. Belhadef and N. Boukli hacene, "Multiband F-PIFA Fractal Antennas for the Mobile Communication Systems", IJCSI International Journal of Computer Science Issues, Vol. 9, Issue 2, No 1, March 2012 
[9]. Muhammad Naeem Iqbal, Hamood-Ur-Rahman, Syeda Fizzah Jilani, Novel Compact Wide Band Coplanar Waveguide Fed Heptagonal Fractal Monopole Antenna for Wireless Applications, 14th Annual Wireless and Microwave Technology Conference (WAMICON), 2013 IEEE

[10]. Pichet Moeikham, Chatree Mahatthanajatuphat, Prayoot Akkaraekthalin, A compact ultrawideband monopole antenna with V-shaped slit for $5.5 \mathrm{GHz}$ notched band, 9th International Conference on Electrical Engineering/Electronics, Computer, Telecommunications and Information Technology (ECTICON), 2012 IEEE

[11]. Peng Gao and Shuang He, A Compact UWB and Bluetooth Slot Antenna for MIMO/Diversity Applications, ETRI Journal, vol. 36, no. 2, Apr. 2014, pp. 309-312

[12]. Guo-Ping Gao, Bin Hu, and Jin-Sheng Zhang, Design of a Miniaturization Printed Circular-Slot UWB Antenna by the Half-Cutting Method, IEEE Antennas And Wireless Propagation Letters, Vol. 12, 2013, pp 567-570

[13]. Basil K Jeemon, K Shambavi, Zachariah C Alex, "A Multi-fractal Antenna for WLAN and WiMAX Application”, 2013 IEEE Conference on Information and Communication Technologies (ICT 2013), pp 953956

[14]. Shih-Yuan Chen, Po-Hsiang Wang, Powen Hsu, Uniplanar Log-Periodic Slot Antenna Fed by a CPW for UWB Applications, IEEE ANTENNAS AND WIRELESS PROPAGATION LETTERS, VOL. 5, 2006, pp 256-259

[15]. Constantine A. BALANIS, “Antenna Theory : Analysis and design”, Third Edition, WILEY, 2006.

[16]. A. Reha and A. Said, "Tri-Band Fractal Antennas for RFID Applications," Wireless Engineering and Technology, Vol. 4 No. 4, 2013, pp. 171-176. doi: 10.4236/wet.2013.44025.

[17]. FEKO 6.3 User's Manual," EM Software \& Systems-S. A, October 013, pp.1-1.

[18]. Paul F.Combes, Micro-Ondes 1-Lignes, guides et cavités, DUNOD, 1996

[19]. Shabana Huda, Anirban Karmakar, Rowdra Ghatak , On the Design of Dual Band Notch UWB Antenna and Fractal Slots on the Ground Plane for Bandwidth Enhancement, Internatlonal Journal of electronlcs \& communlcatlon technologyVo I.5, Issue spl - 2, Jan-March 2014, pp 50-53.

[20]. J. P. Gianvittorio and Y. Rahmat-Samii, "Fractal Element Antennas: A Compilation of Configurations with Novel Characteristics," 2000 IEEE Antennas and Propagation Society International Symposium, Vol. 3, Salt Lake City, Utah, pp. 1688-1691, July 16-21, 2000.

[21]. J. P. Gianvittorio and Y. Rahmat-Samii, "Fractal Antennas: A Novel Antenna Miniaturization Technique, and Applications," IEEE Antennas Prop 